\title{
INVESTIGATION OF CAPACITY ON THE HOLLOW SECTIONS CONNECTIONS WITH STIFFENING PLATE
}

\author{
Mehmet Fenkli 1,*, İlyas Devran Çelik ${ }^{2}$; \\ Nurettin Alpay Kımılli² and Mustafa Sivri ${ }^{3}$ \\ 1 Süleyman Demirel University, Technology Faculty, Department of Civil Engineering, Isparta 32260, Turkey \\ 2 Süleyman Demirel University, Engineering Faculty, Department of Civil Engineering, Isparta 32260, Turkey \\ 3 Süleyman Demirel University, Technical Sciences Vocational School, Department of Construction Technology, \\ Isparta 32260, Turkey \\ *(Corresponding author: E-mail: mehmetfenkli@sdu.edu.tr)
}

Received: 3 September 2015; Revised: 3 April 2016; Accepted: 10 April 2016

\begin{abstract}
Buildings behave according to their geometrical types, the profile specifications of static structural elements and the classifications of their materials. This structural behavior is a kind of structural reaction to an earthquake. This reaction may be absorbed by the ductility of the structure. There is an indefinite situation in the description of the level of ductility for a static system in the earthquake occurrence calculation for the moment-shifting steel-frame system that consists of square or circular profile elements.
\end{abstract}

This objective of this manuscript is to overcome local buckling on welded RHS column/beam assemblies and thereby establish a design algorithm. We conducted experimental analysis under the cyclical loads by added rigidity plate having different dimensional parameters to a RHS at the assembly point. We optimized the design and the dimension of the plate with the expansion of the subject models of the experimental analysis by using the Ansys finite-element program.

Keywords: Turkish Earthquake Code 2007, CHS (Circular Hollow Section), RHS (Rectangular Hollow Section), welded moment resisting connections with rigidity plate, moment resisting steel frame systems, cyclic static loading, moment-rotating relationship, detail of ductility

DOI: $10.18057 /$ IJASC.2017.13.1.3

\section{INTRODUCTION}

The energy of an earthquake and the reaction of the structure against that energy define the behavior of a structure under the seismic effect. In other words, a construction uses kinetic energy, the energy of elastic creep, viscose absorbing energy and hysteric energy to absorb the energy applied by an earthquake. If the absorbing energy is greater than the energy from the earthquake, it is blocked by absorbing energy. Contrastingly, if the absorbing energy is less than the energy from the earthquake, the difference between absorption and the energy of the earthquake is balanced by hysteric energy. This difference is referred to as the ductility of a structure. The behavior of the structure against an earthquake and the rigidity of its static elements are crucial in the design of a structure against an earthquake as well as in regard to ductility. It is not desired to have decreases in load-bearing capacity and rigidity while the ductility increases. For that reason the greater rotations are awaited in plastic behavior with no decrease in load-bearing capacity. However, the static elements have failed to meet the large plastic rotations to compensate for the earthquake, due to some negative situations such as local buckling, cracking and torsion.

Steel static elements, having different assembly and design geometries, are used in practice. The relationship between profile effect and creep is unique to each system and its particular assembly. This situation affects the structure's ability to absorb energy (ductility). The types of materials of the assembly parts (welds, bolts and strengthening plates) in the system, the application quality and 
dimensions are the main factors in the ductility of the steel structure. Therefore, certain details have been developed to prevent brittle breakage in the assembly points at the frame system and to ensure that the assembly points behave in parallel with the ductility of the system. However, the use of measures against the details described in the literature and local creep are for the hot-rolled standard profiles of types I, C, T and L. There are differences in the behavior and creep of the square profiles or static hollow elements commonly used in practice. For that reason it is not possible to consider the square profiles with the details for the standard profiles, nor is it appropriate to conduct analysis according to them.

The local buckling situations described in Euro Code 2003 Section 1-8 and CIDECT Division 3 [7] are shown in Figure 1. Deformations have been reviewed in two parts as axial load and bending effect for the circular profile. They are submitted for comparison in Figure 1.

\section{UNDER THE AXIAL LOAD}
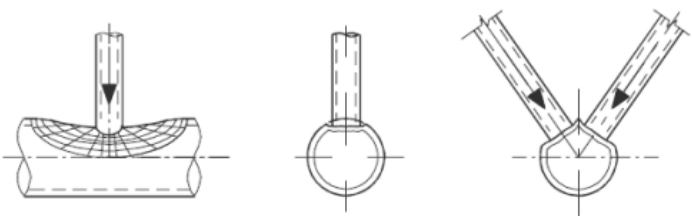

a) The buckling position at the upper head of the column
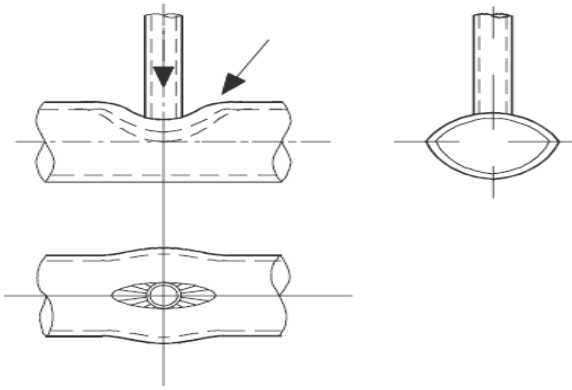

c) The position of local buckling on the body of the column (position of deformation with distention)

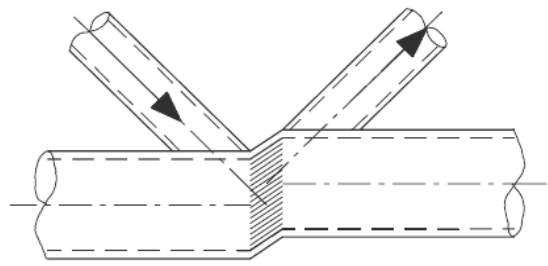

e) The position of deformation at the column panel location
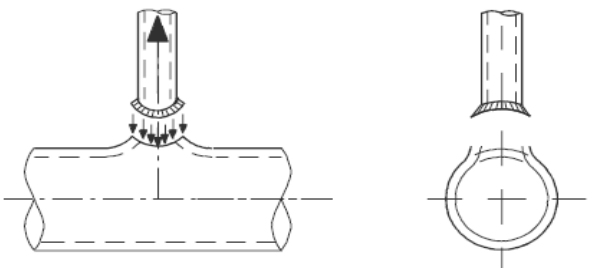

g) The position of rupture depending on tearing at the upper head of the column

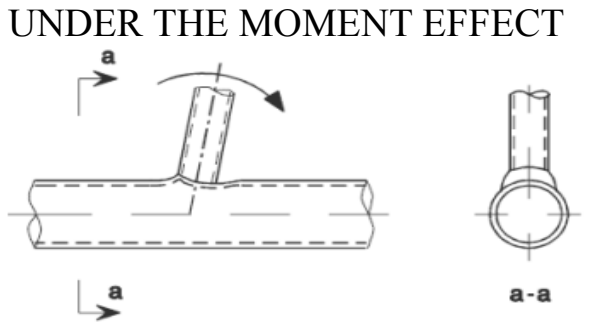

b) The buckling position at the upper head of the column
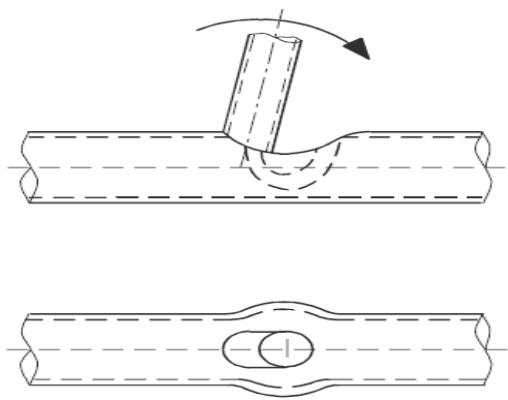

d) The position of local buckling on the body of the column (position of deformation with distention)

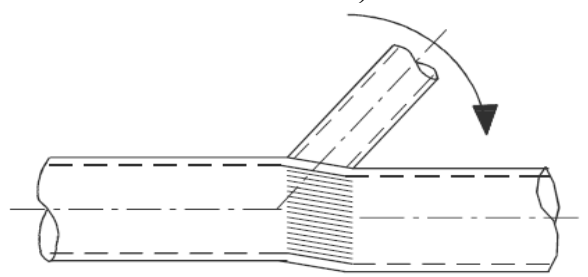

f) The position of deformation at the column panel location

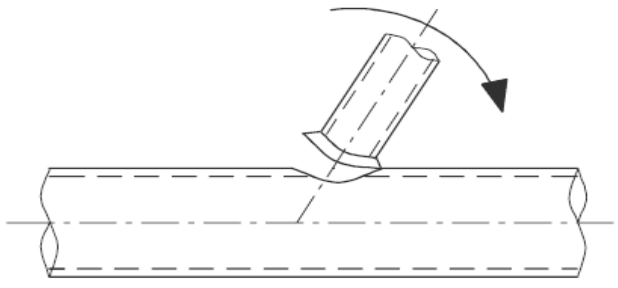

h) The position of rupture depending on tearing at the upper head of the column. 

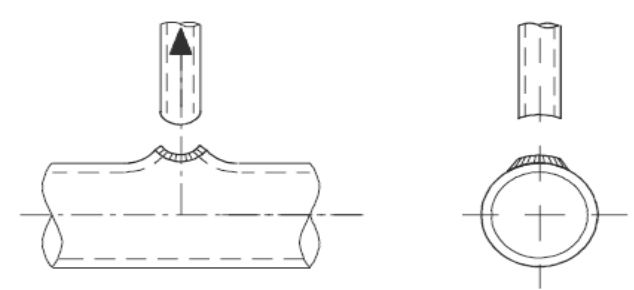

i) The position of rupture at the beam/cross element

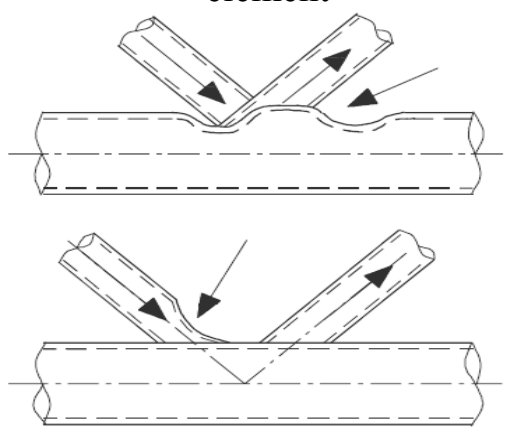

l) The buckling position at the cross element

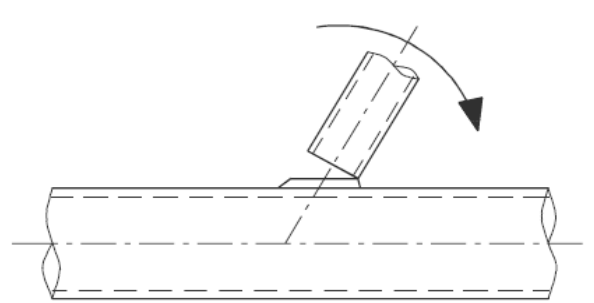

k) The position of rupture at the beam/cross element

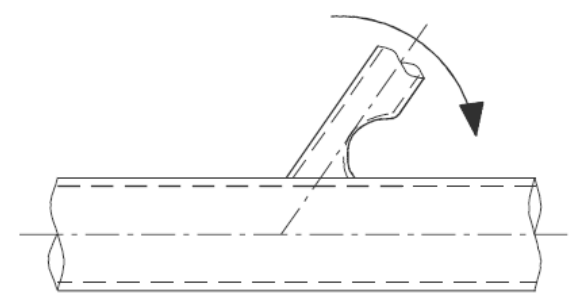

m) The buckling position at the cross element

Figure 1. The Deformation Positions Described for Square-profile Assemblies in EURO Code and CIDECT

The behavior of steel structures under horizontal load is related to the specifications of the material, the geometry of the profile and the details of the assembly. Accordingly, the material and profile specifications are vital in defining the rotational capacity of the assembly. It is preferable not to have brittle breakage at beam-column assembly points, and consequently the assembly points must behave in parallel with the ductility of the system. This ductile behavior at the assembly is one of the most important factors affecting the rotational capacity at the assembly point of the static element. For that reason many studies have been conducted, reviewing the position of creep that could affect the rigidity, ductility and the structural behavior at square-profile assemblies.

The assemblies in node points of the "Vierendeel" system --the first type of shear system to be designed with the use of square profiles-- were used in the studies included in the Design Guide (CIDECT) Euro Code. Moreover, many studies have been conducted in regard to assembly types, representing the rigid and semi-rigid assemblies, including the moment-rotation relationship and strength (Figure 2, Vierendeel-type node point). Rigidity plates have been used to overcome the local bucklings incurred on the profiles. Some examples of the rigidity plates are shown in Figure 2. Moreover, some of the dimensional parameters regarding the plates used for the type- $T$ assembly are covered in this study and included in the Design Guide. Accordingly, it is advised that the $\mathrm{t}$-value of the head plate is equal to or greater than two times the beam thickness involved in the assembly. The limits for the length and width of the plate are defined according to the dimensions of the column or beam included in the assembly. 


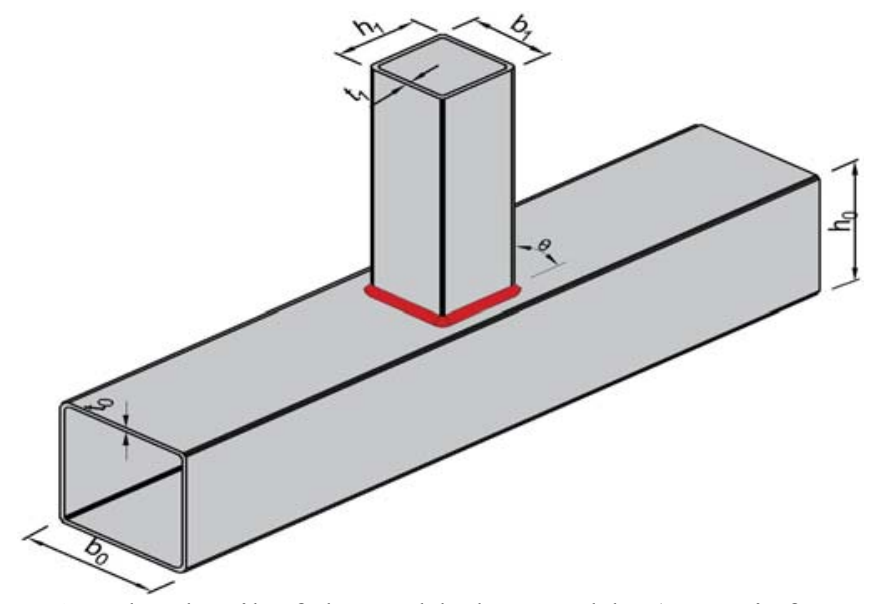

a) The detail of the welded assembly (not reinforced)

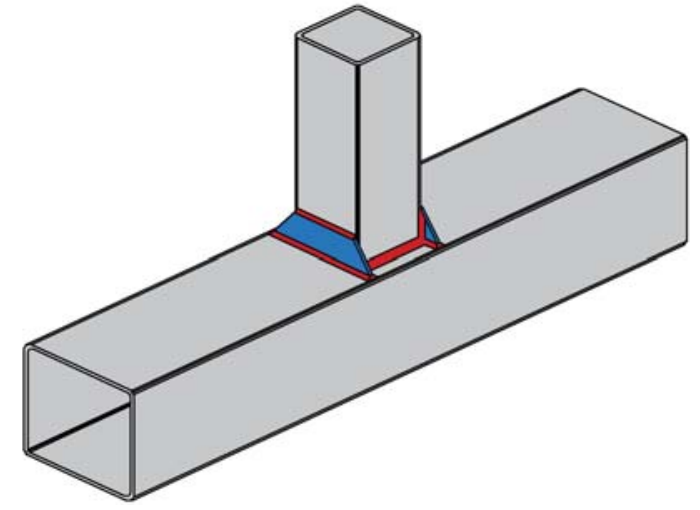

b) The detail of the assembly with reinforcement plate

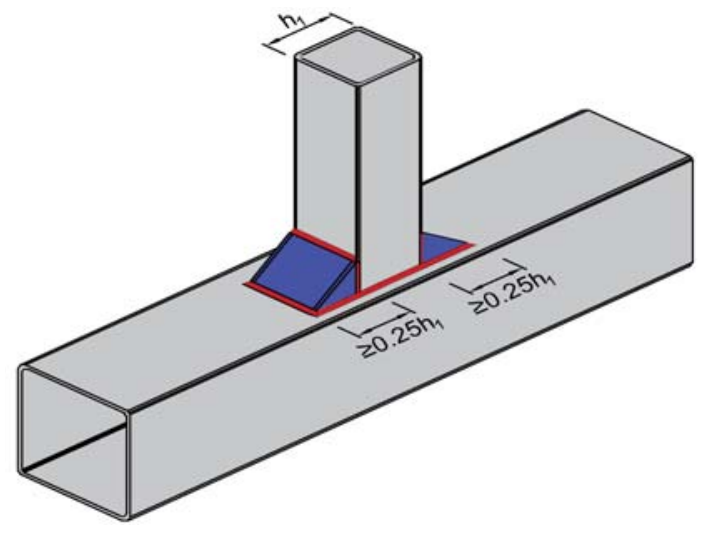

d) The detail of the assembly with amulet element

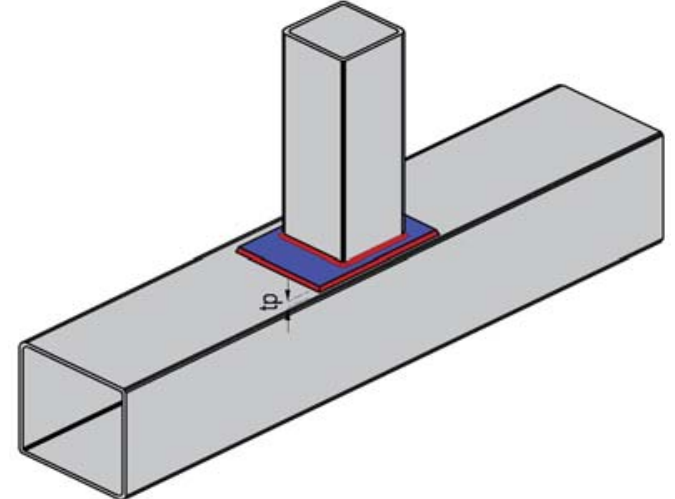

c) The detail of the assembly with head plate

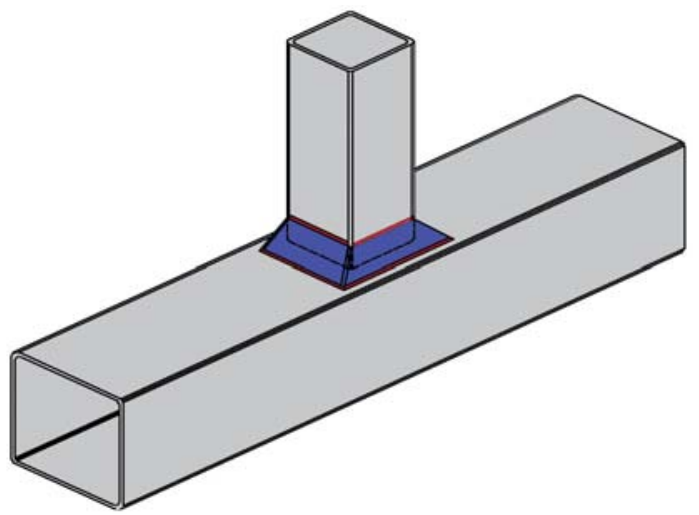

e) The detail of the truncate pyramid assembly

Figure 2. Node Points of Vierendeel Type Rectangular Square Profile (RHS)

Researchers have considered the welded assemblies of square profiles under the effect of moment as rigid and semi-rigid assemblies according to the $\beta\left(b_{1} / b_{0}\right)$ coefficient between the profiles combining the assembly. If $\beta$ is 1.0 , the assembly is rigid, but if $\beta$ is less than 1.0 the assembly is identified as semi-rigid. In the condition of $\beta<1$, it is defined that the rigidity plates are added to the node point to increase the rigidity of the plate according to the details described in Figure $2 \mathrm{~b}, \mathrm{c}, \mathrm{d}$ and e. The frame of this subject has not been expanded to cover all types of square profiles of assembles Design Guide 3 [5]. Other than the rigidity description, the deformation limit and 
maximum stress values have been described in Zhao [23] study for the type-T node point. It is defined that the deformation value occurring at the head of column could be the maximum strength capacity for the type-T assembly. It is shown that the deformation limit for the square profile with welded assembly is up to the coefficient $\beta$, which is described as the ratio of cross/pillar width to the width of the column. Mashiri and Zhao [14], in their study, tied the circular cross/pillar element to the rectangular square profile with the type-T assembly using welds. The profiles used in the assembly of the study are thin-walled, and the wall thickness is equal to $4 \mathrm{~mm}$ or less. There has been identified a model for a column having deformation in determining the displacement limit for the resulting capacity of a node point being assembled in that study. Plastic analysis has been conducted for a digital model designed by using the theory of a strain model derived from the study. It has been verified by comparing the resulting tension value obtained through the use of a digital model and the value acquired from the experimental result. Wang et al. [21] tested the assembly of being in the "I" form and circular profile column against horizontal force under a constant axial load affecting the integrity of the cylinder. The assembly is composed of two different combinations like strong column / weak beam and weak column / strong beam. There were eight experiments in that respect, of which five pertained to the strong column/weak beam combination. The column-strengthening process was applied, being covered by a ring through the use of an additional plate. The strengthening method using a ring was conducted for all eight experimental samples. Additionally, five circular profile columns filled with concrete were used in some examples of the strong column / weak beam design. The experimental analysis showed that a weakened beam gave high seismic performance results in terms of the dissemination of tension and the diffusion of energy under the horizontal load for the five weakened beam samples as the strong column / weak beam combination. It was observed that weakened beam, when used at assemblies, played a key role in structural behavior, while the calculation of the resulting load made a vital contribution in defining the formation order of the plastic joint. It was shown that the ring type of rigidity plate prevented the buckling at the column in the study by Hwang et al. [8], and experimental research has been conducted regarding the strength of structure and the form of the dents at the assemblies, consisting of square beam / circular columns constructed in the form of steel scaffolding. Eight experiments were conducted, whereby the use of monotonic loading experiments showed that the circular columns are more rigid than the rectangular columns. The contribution to the rigidity of concrete filling at the assembly of the square beam / circular column was also reviewed. The mode of dent/collapse could be described more accurately, and it proposed more reasonable values for equivalent body width. Also Duff [6], Redwood [17], Cute [3], Mehrotra and Redwood [15], Lazar and Fang [11], Wardenier [22], Mehrotra and Govil [16], Korol and Mansour [9], Korol and Mirza [10], Mang et al. [12], Davies ve PanjehShahi [4], Szlendak and Brodka [18], Brodka and Szlendak [2], Mashiri et al. [13], Szlendak [19], studied these subjects.

\section{SPECIMENS}

It is aimed to have a design algorithm and prevent local buckling at the assembly of welded square-profile column/beam. In that respect an assembly ( $\beta$ is 0.75 ) composed of D215, 1/5 mm circular column $150 \times 200 \times 4 \mathrm{~mm}$ square beam was tested. Some rigidity plates having different dimensional parameters were added at the assembly point to reach $\beta=1.0$. It is aimed to verify the combination of strong column / weak beam and rigid assembly under cyclical loading. Some experimental samples were tested. We endeavored to optimize the design and plate dimensions whereby the models used in the experimental analysis were extrapolated with the Ansys finite-element program [1]. There has been some undesirable local strain at square-profile assembly parts (column, beam, cross-diagonal) under the effect of bending. The placement and formation of strain affect the capacity of node-point ductility and rigidity. We strove to prevent the local stress at the assembly by using rigidity plates having different dimensional parameters or by changing the 
location and formation of strain. The welded circular profile (D219, 1/5) column and rectangular $(150 \times 200 \times 4 \mathrm{~mm})$ beam were tested under the cyclical horizontal load. The general appearance and dimensional parameters regarding the experimental models are shown in Figure 3. The load was applied to the sample vertically and continuously, and the loading lever and strength conditions of the sample were designed in a hinged manner.

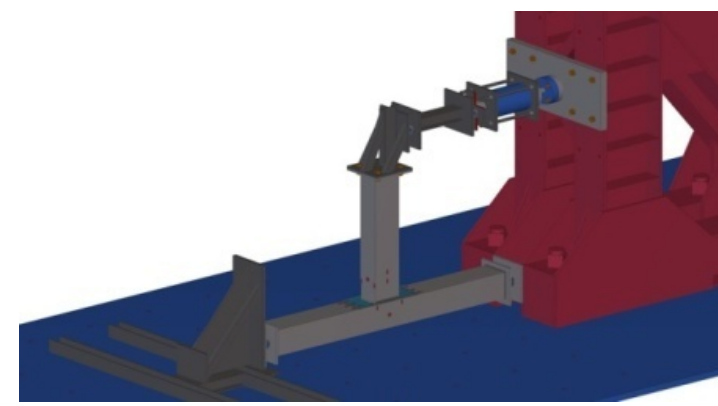

a) Experimental model general view

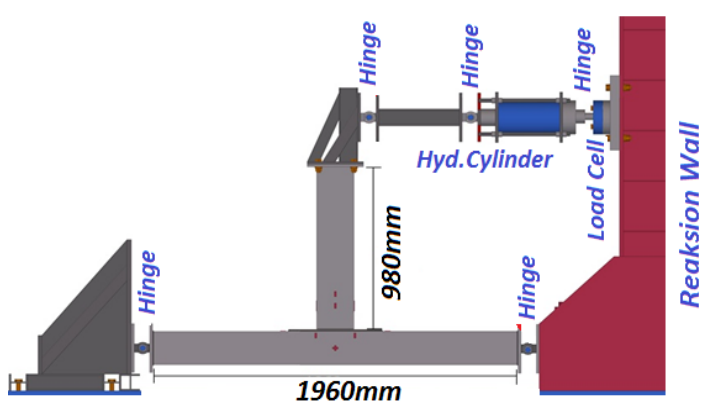

b) Dimension of speciment\&Loading System view Figure 3. General view of experiment model

The dimensional parameters of the rigidity plate added to the column upper head at the assembly were based on alterations on length, width and wall thickness. In that respect there were ten experimental samples, including replicate samples and 37 digital models. The assembly of the column beam without a plate was connected by welding at the reference model of the replicate sample. Experimental samples with rigidity plate the thickness of the plate were consistently selected as $8 \mathrm{~mm}$ while the width and length values were changed. The number of models was increased in the digital models calibrated according to the experimental samples, each being designed for five different calculations of wall thickness. There are some variables of dimensional parameters for the rigidity plates submitted in Fig. 4.

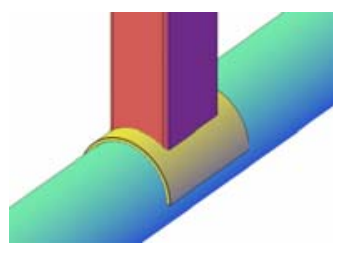

a) Node point general view

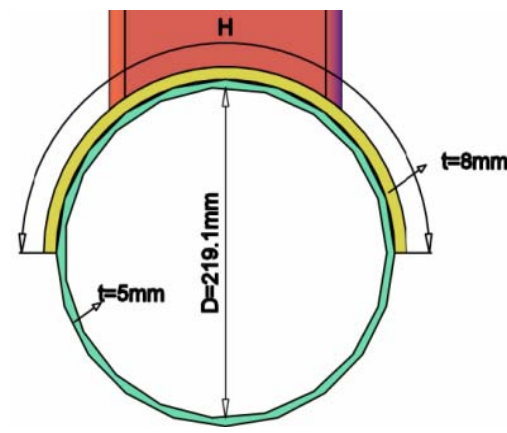

b) The view of dimensional parameter profile of the rigidity plate

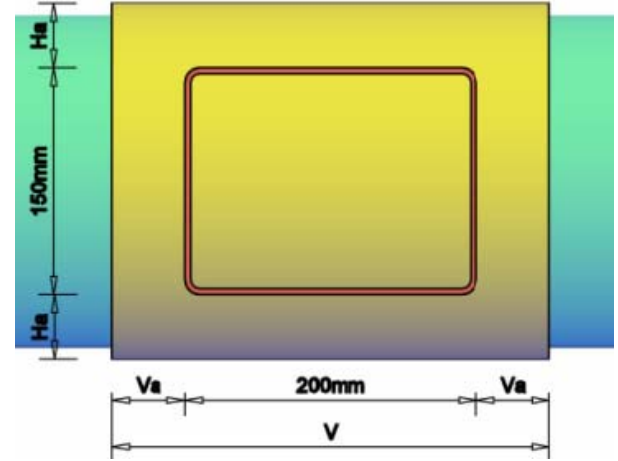

c) The view of the plan of dimensional parameter for rigidity plate

Figure 4 . The dimensional parameter for the of the rigidity plate-rigidity models

The change in length for the plates added to the assembly is identified as (V) and three main groups assigned as 300, 350 and $400 \mathrm{~mm}$. There has been established three sub-parameters more by selecting the width $(\mathrm{H})$ values are 250,300 and $350 \mathrm{~mm}$ in every group below the length V. Experimental analysis has been conducted for 10 experimental models in total (nine are with the rigidity plate, and one is with no plate (replicate sample) for the $8-\mathrm{mm}$ wall thickness. The models having conducted experimental analysis and the dimensional changes used for rigidity plates used at these models are detailed in Table 1. 
Table 1. Plate Dimensions, Wall Thickness for Experimental Samples and the Names of Models

\begin{tabular}{|c|c|c|c|c|c|c|}
\hline \multirow{2}{*}{ Line } & \multirow{2}{*}{$\begin{array}{c}\text { Speciment } \\
\text { No }\end{array}$} & \multicolumn{5}{|c|}{ Rijidity Plate Parameters } \\
\cline { 3 - 7 } & & Va & Ha & V & H & ta \\
\hline 1 & S 0 & - & - & - & - & - \\
\hline 2 & SP1-1/8 & 50 & 25 & 300 & 250 & 8 \\
\hline 3 & SP1-2/8 & 50 & 50 & 300 & 300 & 8 \\
\hline 4 & SP1-3/8 & 50 & 75 & 300 & 350 & 8 \\
\hline 5 & SP2-1/8 & 75 & 25 & 350 & 250 & 8 \\
\hline 6 & SP2-2/8 & 75 & 50 & 350 & 300 & 8 \\
\hline 7 & SP2-3/8 & 75 & 75 & 350 & 350 & 8 \\
\hline 8 & SP3-1/8 & 100 & 25 & 400 & 250 & 8 \\
\hline 9 & SP3-2/8 & 100 & 50 & 400 & 300 & 8 \\
\hline 10 & SP3-3/8 & 100 & 75 & 400 & 350 & 8 \\
\hline
\end{tabular}

We endeavored to optimize the rigidity plate's wall thickness by analyzing the thickness in the limits of 5/6/10 $\mathrm{mm}$ in addition to $8 \mathrm{~mm}$ in the digital models calibrated according to the results of the experimental samples. The plate dimensions, wall thickness and names of the models used for all experimental and digital models are shown in Table 2.

Table 2. The plate dimensions, wall thickness and the names of the models

\begin{tabular}{|c|c|c|c|c|c|c|c|}
\hline \multirow{2}{*}{$\begin{array}{c}\text { Code } \\
\text { Name } \\
\end{array}$} & \multicolumn{4}{|c|}{ Plate Size } & \multirow{2}{*}{\multicolumn{3}{|c|}{ Model Name }} \\
\hline & P1-1 & P2-1 & P3-1 & $\mathbf{t}$ & & & \\
\hline $\mathrm{M}$ & $300 / 250$ & $350 / 250$ & $400 / 250$ & 5 & MP1-1/5 & MP2-1/5 & MP3-1/5 \\
\hline $\mathrm{M}$ & $300 / 250$ & $350 / 250$ & $400 / 250$ & 6 & MP1-1/6 & MP2-1/6 & MP3-1/6 \\
\hline SM & $300 / 250$ & $350 / 250$ & $400 / 250$ & 8 & SMP1-1/8 & SMP2-1/8 & SMP3-1/8 \\
\hline \multirow[t]{2}{*}{$\mathrm{M}$} & $300 / 250$ & $350 / 250$ & $400 / 250$ & 10 & MP1-1/10 & MP2-1/10 & MP3-1/10 \\
\hline & P1-2 & P2-2 & P3-2 & $t$ & & & \\
\hline $\mathrm{M}$ & $300 / 300$ & $350 / 300$ & $400 / 300$ & 5 & MP1-2/5 & MP2-2/5 & MP3-2/5 \\
\hline $\mathrm{M}$ & $300 / 300$ & $350 / 300$ & $400 / 300$ & 6 & MP1-2/6 & MP2-2/6 & MP3-2/6 \\
\hline SM & $300 / 300$ & $350 / 300$ & $400 / 300$ & 8 & SMP1-2/8 & SMP2-2/8 & SMP3-2/8 \\
\hline \multirow[t]{2}{*}{$\mathrm{M}$} & $300 / 300$ & $350 / 300$ & $400 / 300$ & 10 & MP1-2/10 & MP2-2/10 & MP3-2/10 \\
\hline & P1-2 & P2-3 & P3-3 & $\mathbf{t}$ & & & \\
\hline $\mathrm{M}$ & $300 / 350$ & $350 / 350$ & $400 / 350$ & 5 & MP1-3/5 & MP2-3/5 & MP3-3/5 \\
\hline $\mathrm{M}$ & $300 / 350$ & $350 / 350$ & $400 / 350$ & 6 & MP1-3/6 & MP2-3/6 & MP3-3/6 \\
\hline SM & $300 / 350$ & $350 / 350$ & $400 / 350$ & 8 & SMP1-3/8 & SMP2-3/8 & SMP3-3/8 \\
\hline $\mathrm{M}$ & $300 / 350$ & $350 / 350$ & $400 / 350$ & 10 & MP1-3/10 & MP2-3/10 & MP3-3/10 \\
\hline \multicolumn{8}{|c|}{ M (Numerical Model/Ansys), SM (Numerical\&Experimental Model ) } \\
\hline \multicolumn{8}{|c|}{$\begin{array}{l}\text { Note: The notations in this table are the same as those used for all graphs and figures } \\
\text { in the study. }\end{array}$} \\
\hline
\end{tabular}

Analysis Workbench Version 14.0 was used in the analysis of the digital models. The digital models were resized so that the assembly parts (column, beam, rigidity plate) and loading instrument (load lever, strength conditions) could reflect the experimental samples exactly, and these digital models have been divided into their respective finite elements. On one hand, the welded assemblies have been identified as rigid, while on the other hand the connection between the rigidity plate-column upper head has been described as frictional in the context of numerical 
analysis. The loading lever and strength points of the samples were modeled as having stable strength and single-way rotational latitude. The identification of model materials for numerical analysis was defined using the result of tensile testing in regard to the examples gathered from the samples. The stress/transformation graphs, obtained after the tensile test and the dimensions of example used in the tensile tests, are shown in Figure 5. (TS EN ISO [20], the "Metal materials, Tensile Test" standards, was used to determine the dimensions of samples for the tensile tests.)

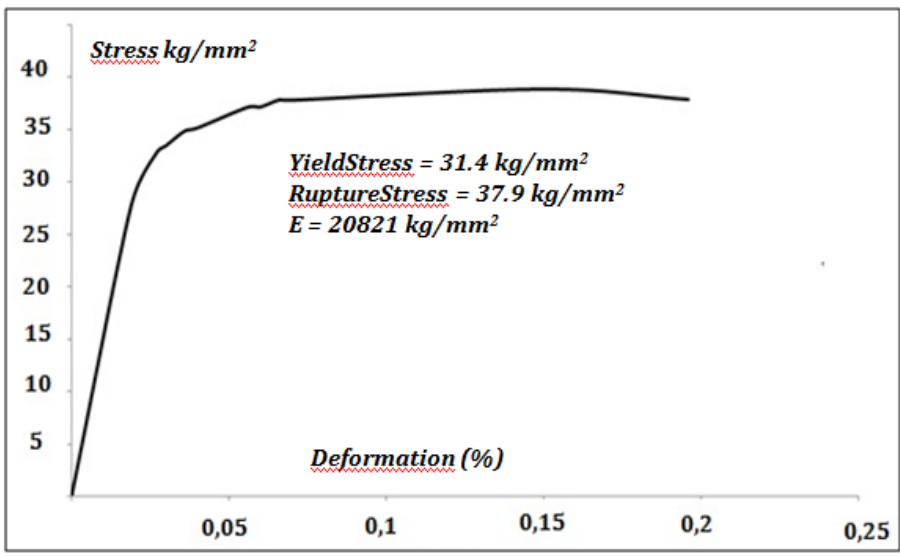

a) Stress/creep graph

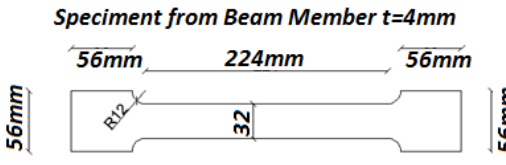

Speciment from Column Member $t=5 \mathrm{~mm}$

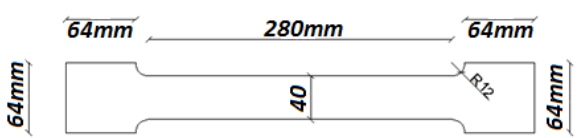

b) Sample dimensions

Figure 5. The results of the tensile test

\section{RESULTS OF THE STUDY}

The replicate sample (SO) was tested first to see the contribution of the rigidity plate added to the assembly in the study, whereby it could serve as a reference for other analyses. A local buckling occurred at the column upper head of the assembly location of the column/beam at the replicate sample under cyclical loading. The assembly could not have the behavior of the strong column / weak beam combination, and consequently creep occurred at the column first. For that reason no sufficiently rigid hinge or mechanism was found to be applicable to the assembly. Some views regarding the deformations at the replicate sample are shown in Figure 6. based on that figure, some local buckling was observed, originating from the corners of the beam at the column upper head, and the capacity of the system has been dramatically less than the theoretical capacity:

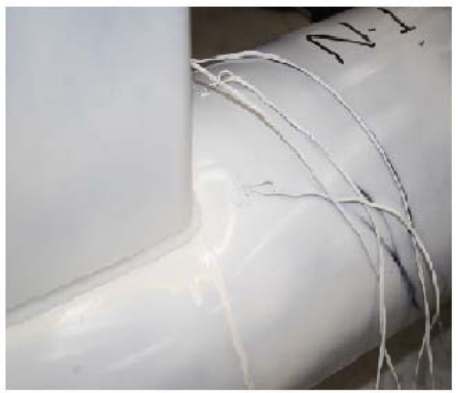

a) Local deformation at column upper head

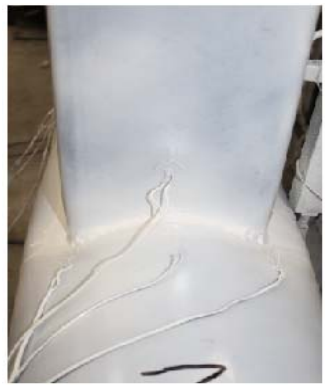

b) Local deformation at pressure location Figure 6 . The view of deformation of column upper head at replicate sample

The rigidity plate was used other than the replicate sample to prevent column deformation. It was used to prevent the local deformations that otherwise occurred on the column for all models modified with rigidity plates. Consequently, the rigidity of the node point increased and creep was observed at the beam instead of the column. The deformation under the bending effect at the beam 
is a particular kind of mechanism, so the design principle of the strong column / weak beam was met. There are some views, demonstrating appearance after the load application, in Figure 7 regarding the experimental samples having a fixed wall thickness but different dimensional parameters.

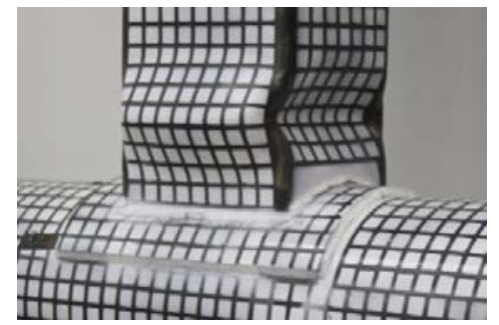

a) $\mathrm{SP} 1-1 / 8$

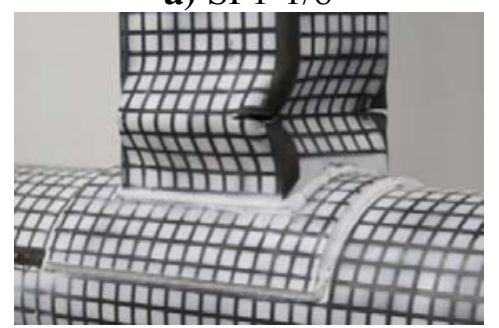

d) $\mathrm{SP} 1-2 / 8$

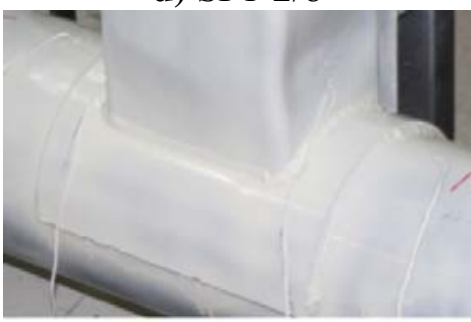

g) $\mathrm{SP} 1-3 / 8$

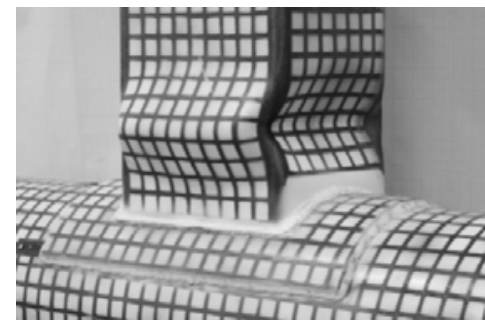

b)SP2-1/8

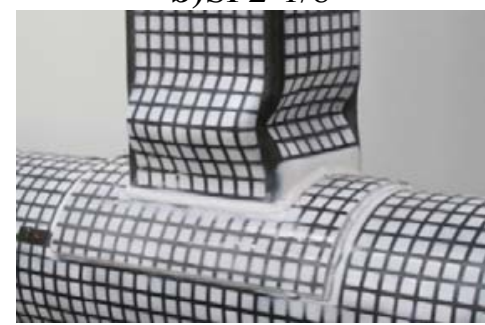

e) $\mathrm{SP} 2-2 / 8$

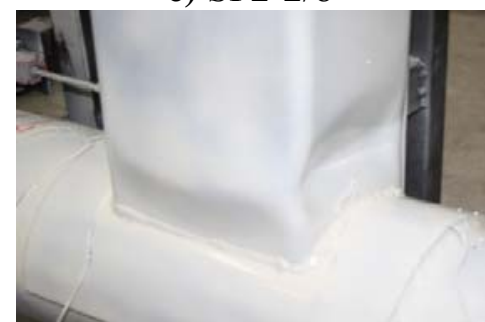

h) $\mathrm{SP} 2-3 / 8$

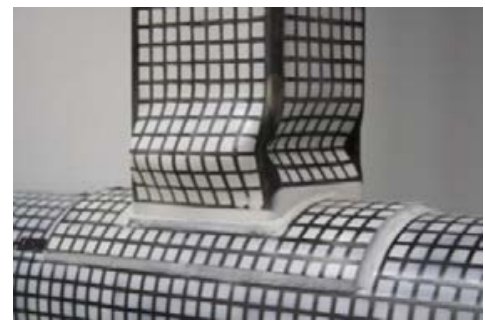

c) $\mathrm{SP} 3-1 / 8$

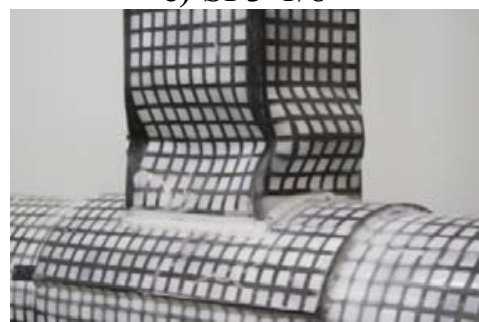

f) $\mathrm{SP} 3-2 / 8$

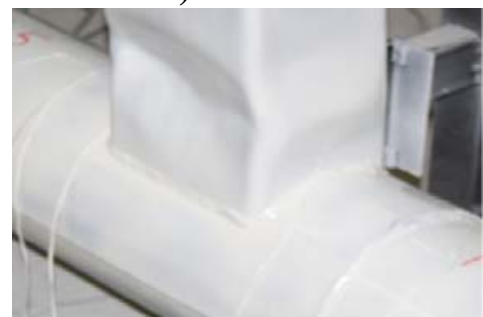

l) $\mathrm{SP} 3-3 / 8$

Figure 7. Deformation on the column after loading at some models.

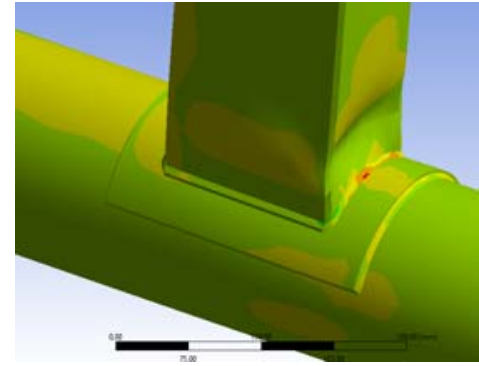

a) $\mathrm{SMP} 1-1 / 8$

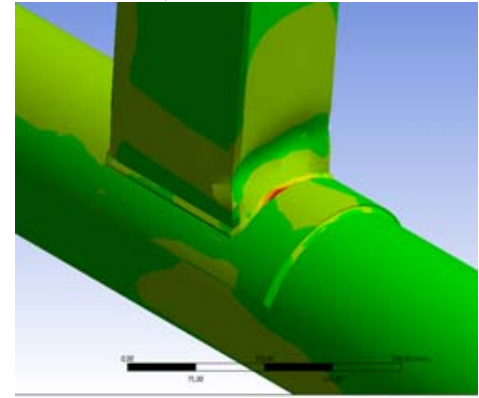

d) SMP $1-2 / 8$

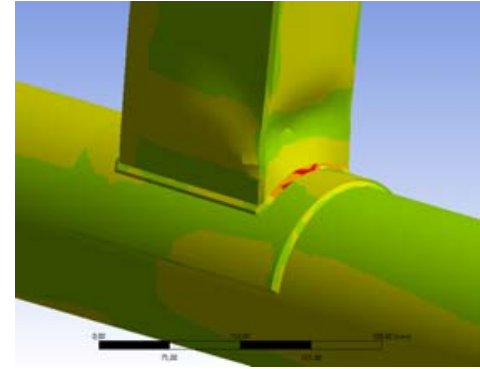

b)SMP $2-1 / 8$

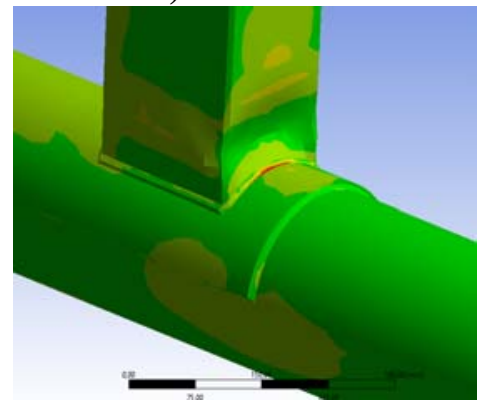

e) $\mathrm{SMP} 2-2 / 8$

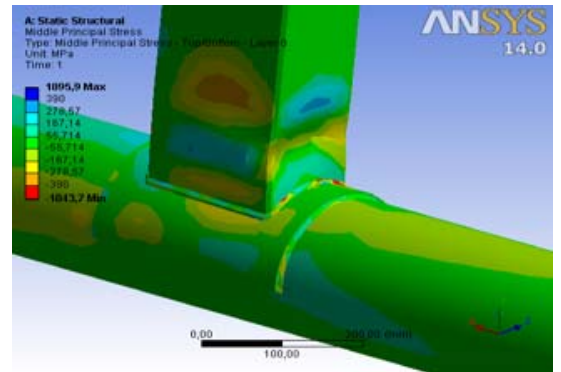

c) $\mathrm{SMP} 3-1 / 8$

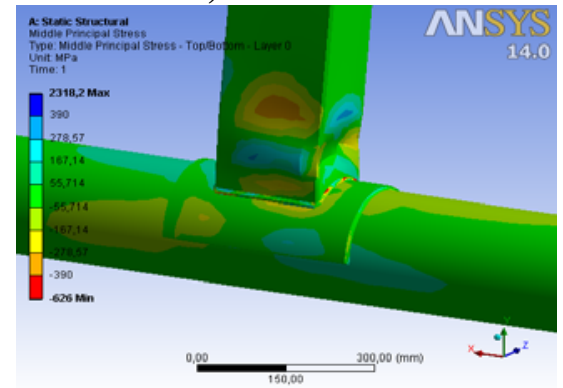

f) $\mathrm{SMP} 3-2 / 8$ 


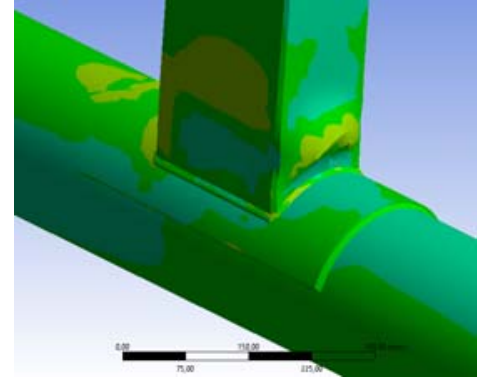

g) $\mathrm{SMP} 1-3 / 8$

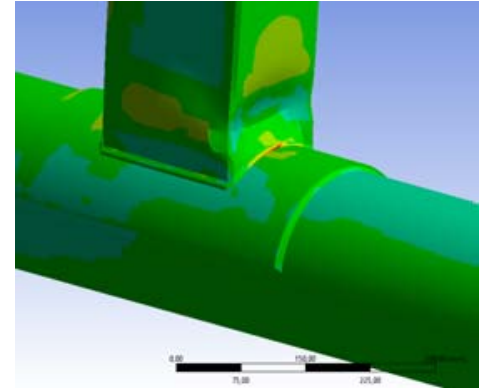

h) $\mathrm{SMP} 2-3 / 8$

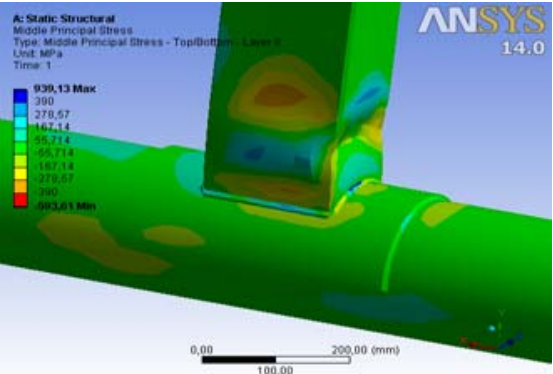

l) $\mathrm{SMP} 3-3 / 8$

Figure 8. Deformation on the joint after loading at numerical models.(ANSYS Work Bench)

It could be seen that the increase in the "V" and " $\mathrm{H}$ " values affects the formation and the location of the hinge on the beam after the review of the figures. The deformation on the beam at the samples with $\mathrm{P} 1(1,2,3), \mathrm{P} 2(1,2,3)$ plates is concave at the head and convex at the body. However, it has been observed that the samples SP3-2/8 and SP3-3/8, having the maximum lengths of "V" and "H," departed from the node point by sliding and that the resulting deformation was convex at the head of the beam but concave at the body. A similar situation was identified in the digital models analyzed for those samples. The situation could be explained whereby the column rigidity increases in parallel to the increase in the length of the plate, causing the stress on the beam to play a more active role in creep.

The load-displacement graphs attained from experimental analysis are submitted in Figure 8. The comparative graphs have been established according to the dimensions of the rigidity plate used with the samples. The width of the plate is $250 \mathrm{~mm}$ (fixed), while the length "V" has some alteration values of 300, 350 and $400 \mathrm{~mm}$ in the graphs in Figure 8. This fixed-width value is the thinnest among the variations used in this study. It was observed that all the samples achieved a nearly twofold capacity increase, far exceeding the reference value in regard to capacity with rapid change, depending on the mechanism at the beam. It was also identified that while the contribution of the rigidity plates to rigidity and capacity gives very similar results, the model with the shortest plate $\mathrm{P} 1(300 / 250 / 8)$ gave the peak value. The same situation is observed at the graphs in Figure $8 \mathrm{~b}$ and c. The width of the plate is $300 \mathrm{~mm}$ in Figure 8b, and the widest plate (350) is in Figure 8c. The increase in the width of the plate, affecting the wrapping effect surrounding the column, did not contribute to the capacity in any significant degree. While plates P1 and P2 with a wall thickness of $5 \mathrm{~mm}$ could reach the others, plate P3 with a $5 \mathrm{~mm}$ wall-thickness value gave a dramatically different result in the condition whereby the wall thickness was reviewed together with the length and thickness.

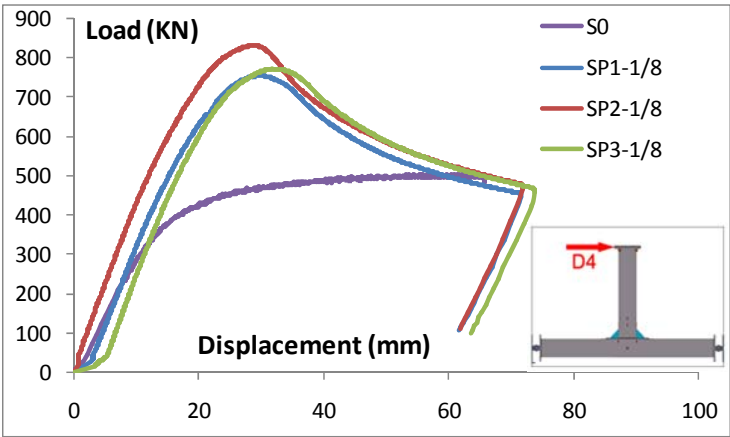

a) $\mathrm{SP} 1,2,3-1(8)$

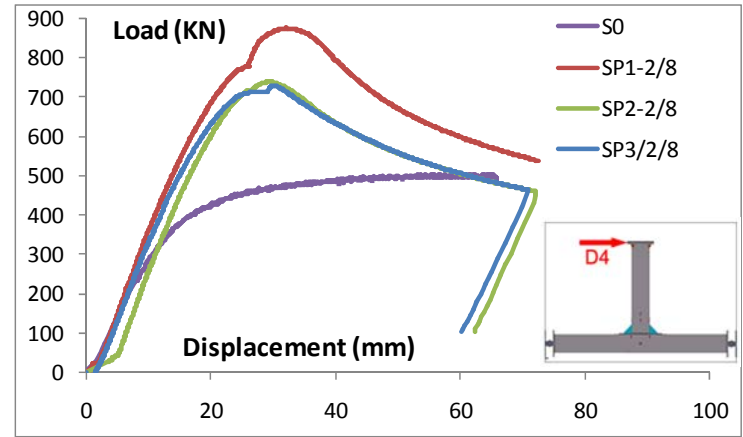

c) $\mathrm{SP} 1,2,3-3(8)$ 


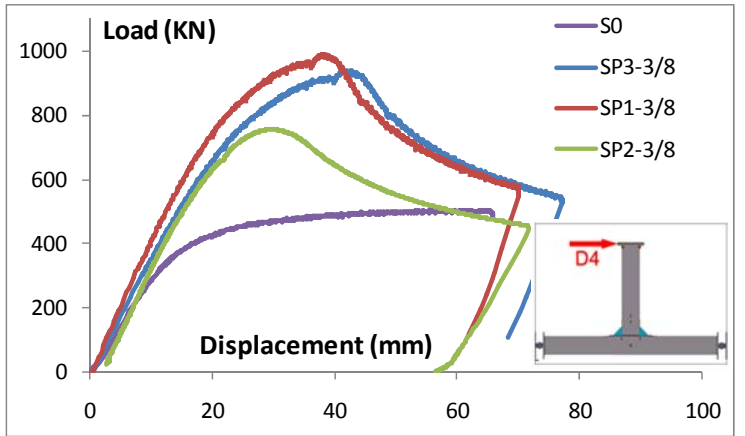

b) $\mathrm{SP} 1,2,3-2(8)$
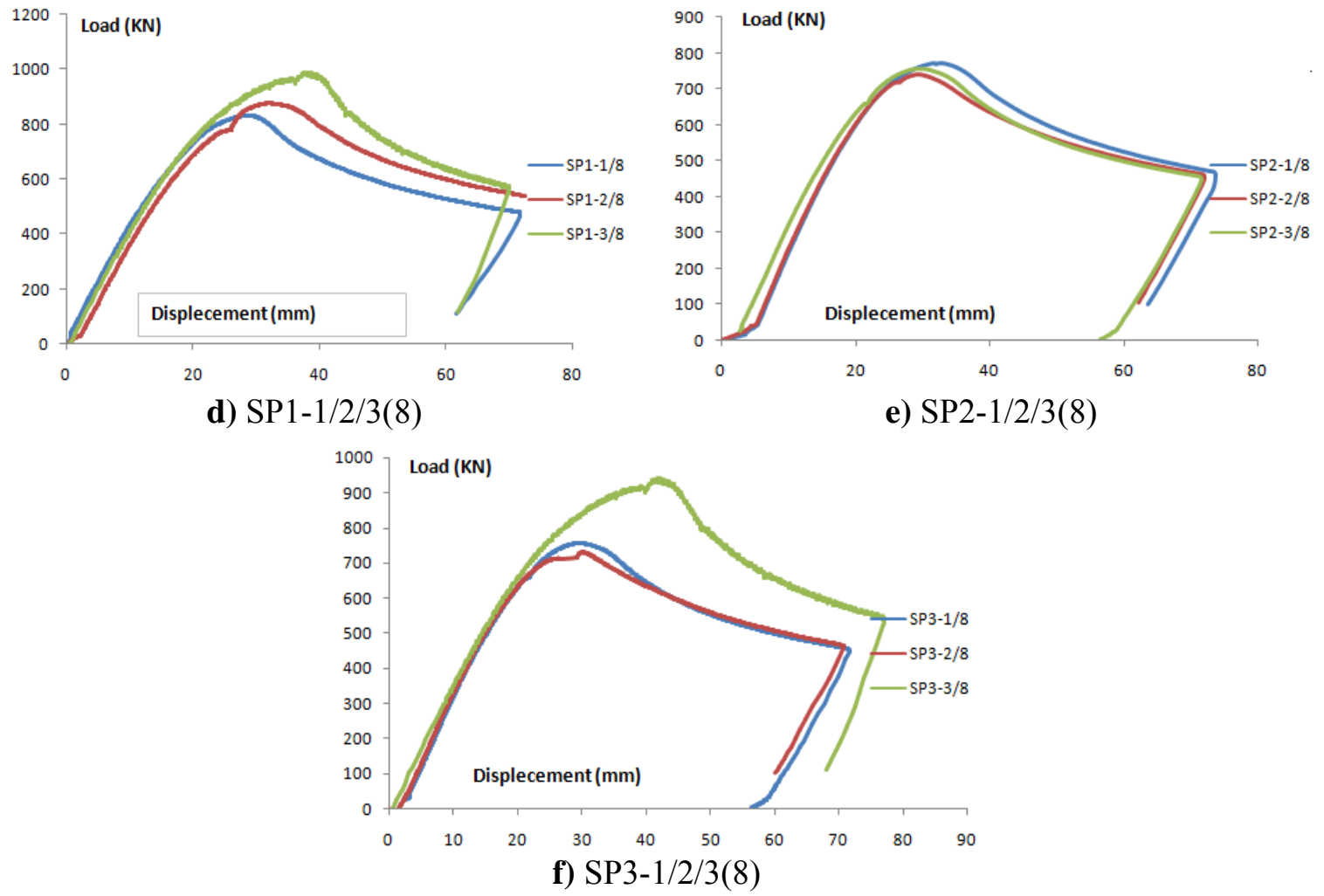

Figure 8 . The comparison of capacity graphs regarding the experimental models of groups 1,2 and 3.

The number of model has been increased and there has been a change only in the wall thickness of the rigidity plate $(5 / 6 / 8 / 10 \mathrm{~mm})$ by fixing the dimensional parameters for all models for which experimental analysis was completed. The load-displacement graph derived from the results of analysis is shown in Figure 9. The blue-colored curves (dashed line) denote experimental analysis, the red colored curves (dashed line) denote numerical analysis regarding that experiment. Based on the graph, the data obtained from digital models has conformity with the experimental models. The alterations of wall thickness/capacity for all dimensions and the behaviors of node points were not changed by excluding the dimensions of plates P3-2 and P3-3 from the numerical analysis or experimental analysis. Only the wall thickness of $5 / 6 \mathrm{~mm}$ at plates with the greatest dimensional parameters gives a different result. Even in this situation there has been a mechanism at the beam, and consequently creep has been prevented. 


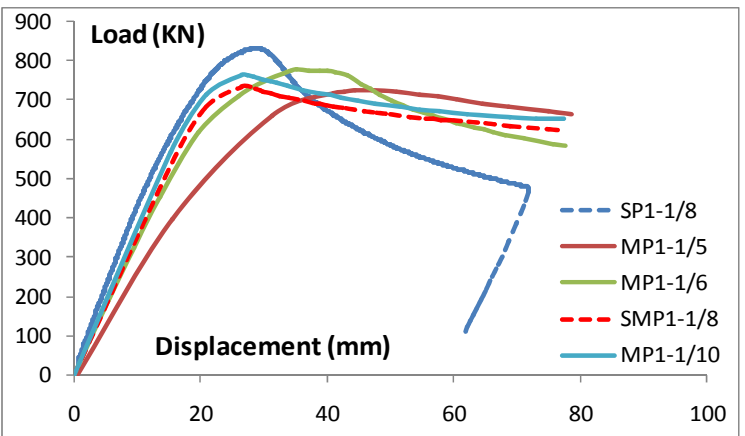

a) $\mathrm{P} 1-1 / 5-6-8-10$

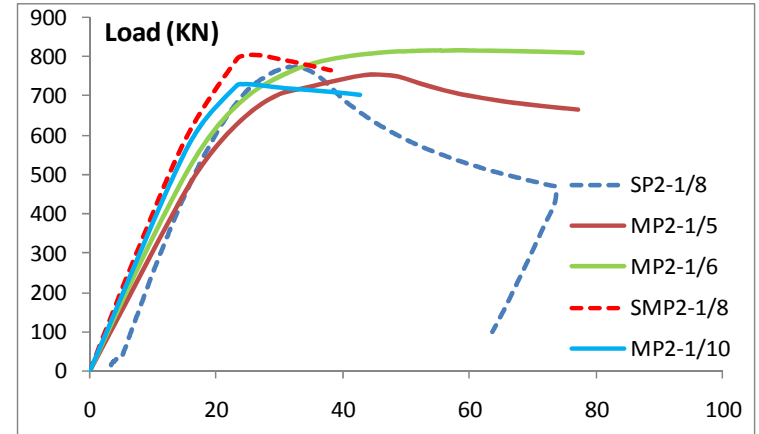

b) $\mathrm{P} 2-1 / 5-6-8-10$

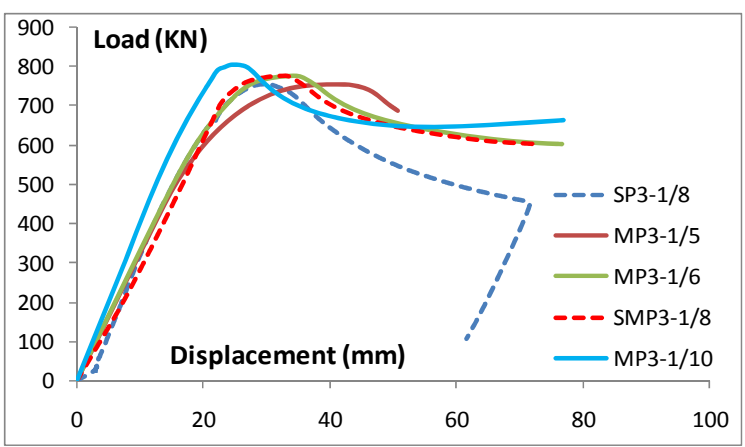

c) $\mathrm{P} 3-1 / 5-6-8-10$

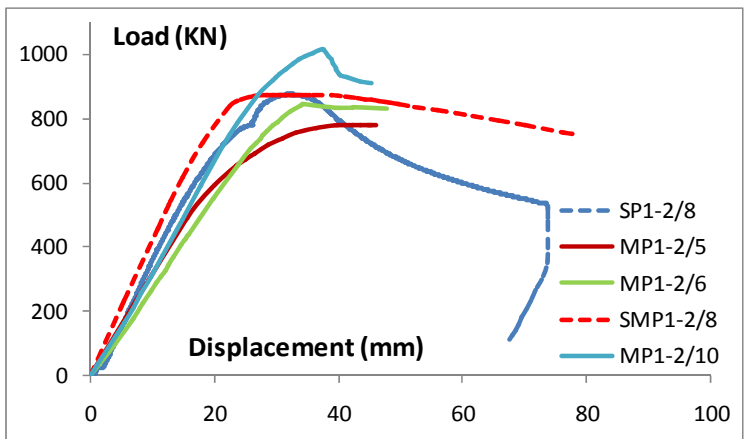

d) $\mathrm{P} 1-2 / 5-6-8-10$

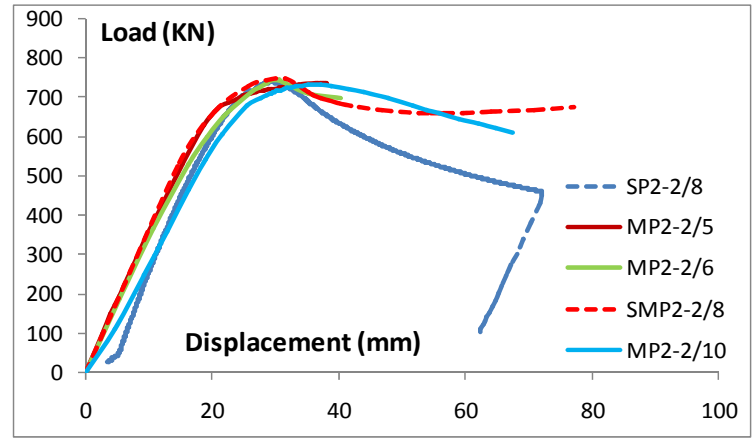

e) $\mathrm{P} 2-2 / 5-6-8-10$

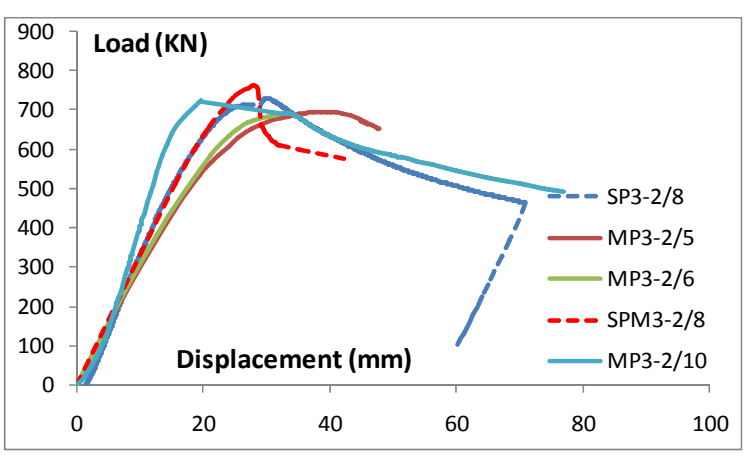

f) $\mathrm{P} 3-2 / 5-6-8-10$ 


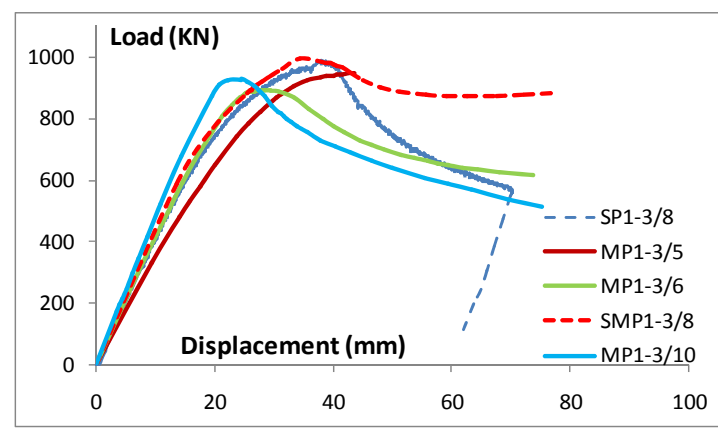

g) $\mathrm{P} 1-3 / 5-6-8-10$

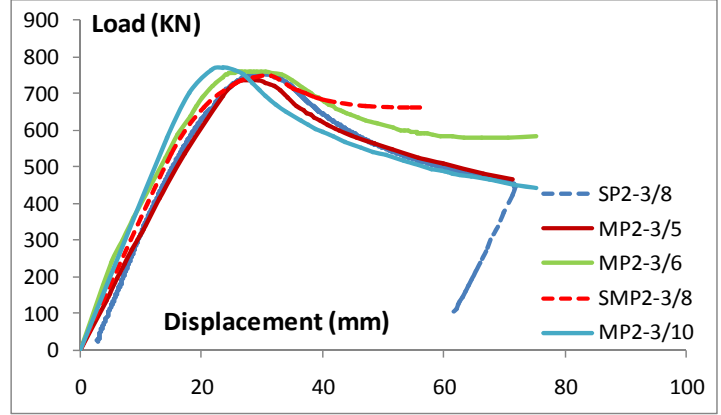

h) $\mathrm{P} 2-3 / 5-6-8-10$

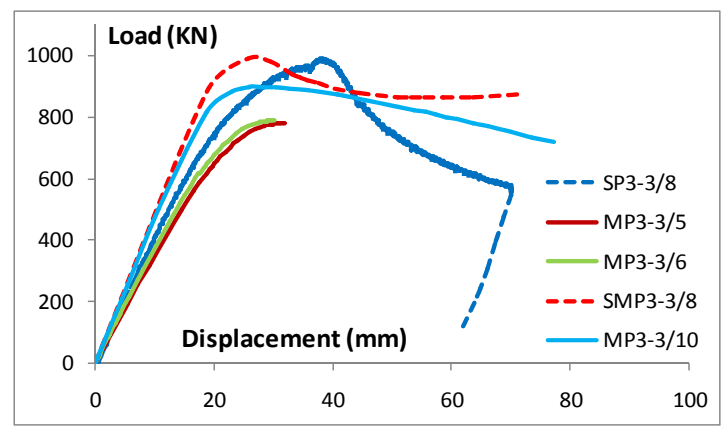

1) $\mathrm{P} 3-3 / 5-6-8-10$

Figure 9. Comparison of capacity graphs regarding the experimental and digital models of groups 1, 2 and 3

We obtained increases in capacity, ductility and rigidity at the assembly with the addition of a rigidity plate to the assembly. The rigidity alterations of experimental and digital models are shown in Figure 10. There is a comparison of rigidity, depending on the alterations of dimensional and wall thickness of plates P1, P2 and P3 in Figure 10a, b and c. There is also another comparison of rigidity with some alterations in the values of width and the fixed values of the lengths of plates $\mathrm{P} 1$, P2 and P3 in Figure 10d, e and f. It is observed that the same rigidity values are obtained with the same wall thickness at plate P1 for the width of 250 and $300 \mathrm{~mm}$, but there is an increase in the rigidity values for the width of $350 \mathrm{~mm}$. The maximum results have been obtained at the narrowest profile of $250 \mathrm{~mm}$ at plate P2. However, while the values obtained from $350 \mathrm{~mm}$ at plate P3 seem greater, a significant difference was not obtained. Thus, the rigidity changes were stable at the same values for the same wall thickness. The increase in wall thickness, excluding some extraordinary situations, gives results in parallel to this increase in terms of wall thickness. There is a comparison regarding the effect of the length alterations on the rigidity node point for the same width values of plates P1, P2 and P3, as shown in the graphs of Figure 10d, e and f. We found that the deformation in length made a positive contribution to rigidity, as shown in the graphs, and that the width of the rigidity plate has been fixed while varying the length. The rigidity has been increased in parallel with the alteration in wall thickness. 


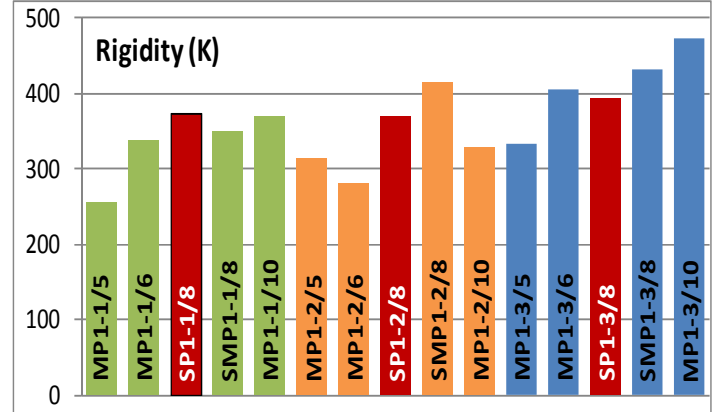

a) $\mathrm{P} 1-1, \mathrm{P} 1-2, \mathrm{P} 1-3(\mathrm{t}=5-6-8-10)$

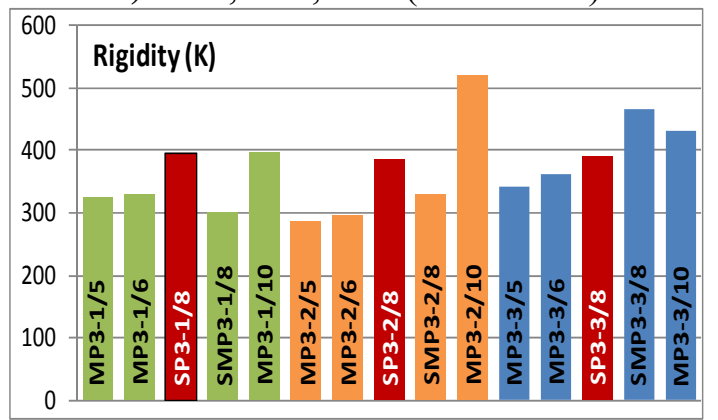

c) $\mathrm{P} 3-1, \mathrm{P} 3-2, \mathrm{P} 3-3(\mathrm{t}=5-6-8-10)$

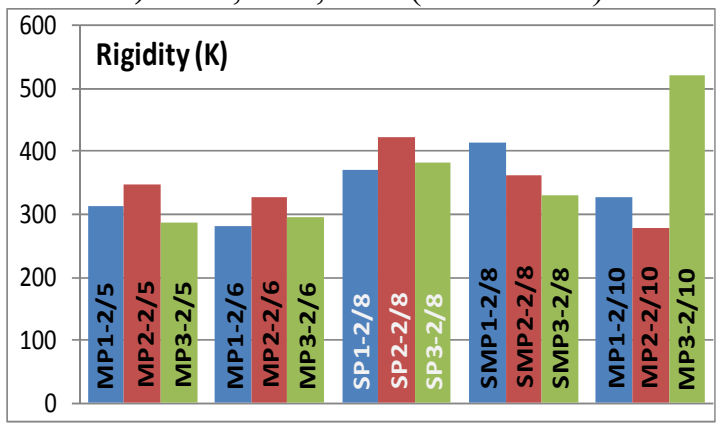

e) $\mathrm{P} 1-2 / \mathrm{P} 2-2 / \mathrm{P} 3-2(\mathrm{t}=5-6-8-10)$

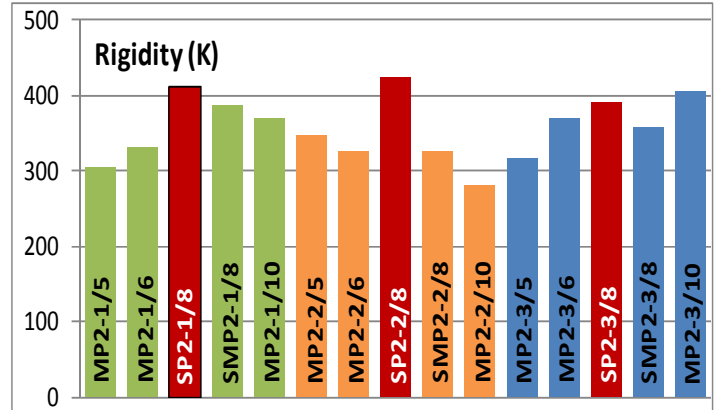

b) $\mathrm{P} 2-1, \mathrm{P} 2-2, \mathrm{P} 2-3(\mathrm{t}=5-6-8-10)$

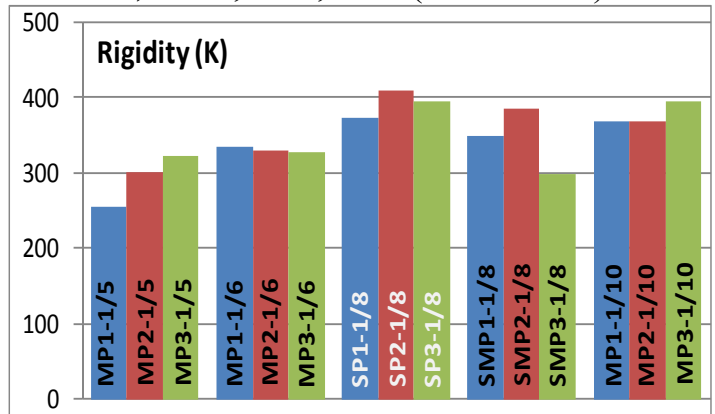

d) $\mathrm{P} 1-1 / \mathrm{P} 2-1 / \mathrm{P} 3-1(\mathrm{t}=5-6-8-10)$

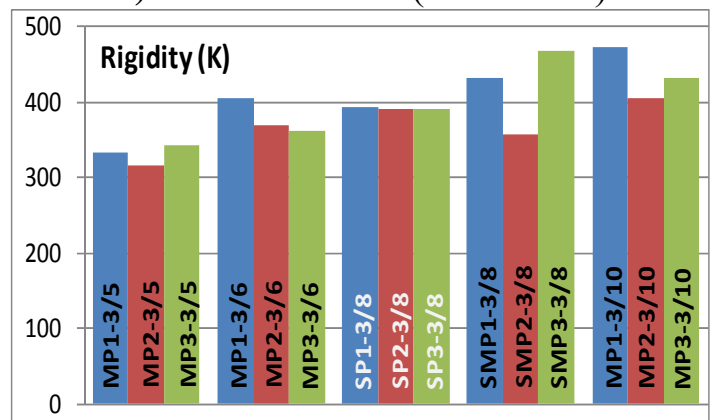

f) $\mathrm{P} 1-3 / \mathrm{P} 2-3 / \mathrm{P} 3-3(\mathrm{t}=5-6-8-10)$

Figure 10. Comparison of rigidities regarding the experimental and digital models of groups 1 , 2 and 3.

\section{RESULTS AND CONCLUSIONS}

The replicate sample and the models with rigidity plates were reviewed from their experimental and numerical aspects. The rigidity plate has been used to prevent the effects of local buckling on the column at this assembly under bending effect. It has been tried to increase the capacity and rigidity of the node point through changes in the dimensions of the plate. The samples, analyzed in that respect, were divided into three main groups in terms of the rigidity plate used, and each group was divided into three sub-models in terms of plate width. Thus there were three models having P1 (Length $\mathrm{V}=300 \mathrm{~mm}$ ) $\mathrm{H}=250 / 300 / 350 \mathrm{~mm}$. We analyzed a total of 10 samples experimentally, including the replicate sample. There were three models having P1 (Length $\mathrm{V}=300 \mathrm{~mm}$ ) $\mathrm{H}=250 / 300 / 350 \mathrm{~mm}$, three models having $\mathrm{P} 2(\mathrm{~V}=350 \mathrm{~mm}) 250 / 300 / 350 \mathrm{~mm}$ and three models having P3 (V=400 $\mathrm{mm}$ ) 250/300/350 $\mathrm{mm}$. All the models were subjected to experimental analysis. The number of models, however, was extended through the use of alterations $(t=5 / 6 / 8 / 10 \mathrm{~mm})$ in the width of the plate by fixing the plate dimensions for all models prior to experimental analysis. A parameter was included in the study by reviewing the effect of wall thickness on behavior. The 
plate, added to the assembly, was reviewed in terms of length $(\mathrm{V})$, width $(\mathrm{H})$ and wall thickness $(\mathrm{t})$, and the effect of each plate on the capacity and rigidity of the assembly was examined.

It was observed that the rigidity panels added to the assembly made positive contributions to the capacity, as demonstrated by all the capacity graphs obtained through experimental and numerical analyses. The most significant increase in capacity was obtained from plate P1 in Figure 10a, b and c, thereby demonstrating the alteration of capacity according to the fixed width and alterations in length. The rigidity plates were attached to the column by welding across the plate edges. For that reason, while the plates under the bending effect deformed with the column under pressure, the plates were forced to creep apart from the surface of the column. Consequently, the more the plate was extended, the more the potential for deformation increased. The capacity and rigidity were affected in a negative way.

Additionally, the cross-height was used as a parameter to increase the effect of wrapping on the column and to limit this situation in the freedom of deformation. The coverage area on the column was increased by choosing the width values of $250 \mathrm{~mm}, 300 \mathrm{~mm}$ and $350 \mathrm{~mm}$. The change in capacity for the number P3-3 (V=400 $\mathrm{mm} ; \mathrm{H}=350 \mathrm{~mm})$ with maximum width was increased $30 \%$ in comparison with the models of "H" value $(250$ and $300 \mathrm{~mm})$ in the situation using the longest plate P3, while the contribution of increase in width to the capacity at plates P1 and P2 did not change significantly. It was identified that the creep (despite not being visible to the naked eye) for the models used plates P1 and P2 with the lengths of 300 and $350 \mathrm{~mm}$ by reviewing the figures at the plate edges, thus reaching the plastic area, and that the decline reached a level beyond the linear limit. For that reason the rigidity of the node point decreased and then the increase of capacity reached its limit. However, for the model that used the longest plate in terms of height and width, the situation of expanding the stresses on the column to the larger area helped keep the stresses within the linear limits. In that respect, the loss of capacity and the rigidity were not experienced and the mechanism on the beam was identified as an alteration of capacity.

Another reason for the increase in capacity is that the circular profile column's reaction to the reversible loads was equal and continuous, depending on the specifications of the column profile. However, the variable behavior of the plate added to the assembly under the effect of pressure and tensile strength changed the reaction of the column. Thus the increase of the wrapping effect on the column of the plate limited the deformation and stress on the plate and the column under the reversible loads and helped keep the stress within the linear limits by using the advantages derived from the profile geometry of the circular column.

Additionally, the increase in the wrapping effect of the plate identified the location of hinge on the beam. For some conditions in which plates P1, P2 and P3-1/2 were used, the distance from the hinge to the node point was 40,50 or $60 \mathrm{~mm}$. The increase in capacity can be explained by the value of $90 \mathrm{~mm}$ for plate $\mathrm{P} 3-3$.

Numerical analysis revealed the effect of wall thickness on the capacity of the node point, rigidity and behavior. The increase in the rigidity of the column was accomplished, resulting in a mechanism at the beam for all the models under cyclical loading (i.e., the models to be prepared for all plate dimensions). When certain results are excluded, the capacity values are in parallel. The loss of capacity on the beam with t-values of $8 \mathrm{~mm}$ and $10 \mathrm{~mm}$ resulted in the rapid loss of load, as shown in the graphs. However, in some analyses in which the t-values were 5 and $6 \mathrm{~mm}$, the curve gave greater absorption and smooth results. The capacity alterations of the models having wall thickness of 5 or $6 \mathrm{~mm}$ at P3-3 are different from the others. It has been observed that a wall thickness of $5 \mathrm{~mm}$ or $6 \mathrm{~mm}$ has not been sufficient in comparison with the others in the situation with the plate length $(400 \mathrm{~mm})$ at the assembly modified through the use of a plate. 
Rigidity plate that are used in preventing the local buckling in column member. In literature dimentional parameters of this plate are defined in terms of width and wall thickness that are related with dimentional of connection members. Such as According to design codes; width of plate sholud be equal to twice diameter of column and also thicnes of plate should be equal to twice web thicnes of beam. As shown the parameters are connected to one value. In this study; according to the results; parameters were defined based on a range rather than a single value . our range of dimentional parameters are shwed as follows.

If it is preferable to overcome the local deformations using rigidity plate at this type of assembly, in light of the data gathered through experimental and numerical analysis:

- The length $V_{b}$ for the plate should be at the interval of $0,25 V_{b} \leq V_{p} \leq 0,5 V_{b}$;

- If $V_{p}$ length is $0,25 V_{b} \leq V_{p} \leq 0,375 V_{b}$ then wall thickness is tc $\leq \mathrm{t} \leq \mathrm{tb}$, The width of the plate $\mathrm{H}$ should be selected from the interval of $2 \mathrm{r} \leq \mathrm{H} \leq \pi \mathrm{r}$ ( $\mathrm{r}$ is radius for the column); and

- If the length $V_{p}$ of plate $V_{p}=0,5 V_{b}$ then it is offered that the wall thickness is $\mathrm{t} \geq 2 \mathrm{tb}$ and $H$ value (the width of the plate) is $H=\pi r$.

\section{REFERENCES}

[1] ANSYS 14.0 Workbench [Computer software]. Canonsburg, PA, Ansys.

[2] Brodka, J. and Szlendak, J., "Strength of Cross Joints in Rectangular Hollow Sections", In XXVI Scientific Conference of the Civil and Hydraulic Engineering Section of the Polish Academy of Science and of the Science Division of PZITB, 1980.

[3] Cute, D., Camo, S. and Rumpf, J.L., "Welded Connections for Square and Rectangular Structural Steel Tubing" In Research Report No. 292-10, 1968, Drexel Institute of Technology Philadelphia, PA.

[4] Davies, G. and Panjehshahi, E., "Tee Joints in Rectangular Hollow Sections (RHS) under Combined Axial Loading and Bending" In 7th International Symposium on Steel Structures, 1984.

[5] Design Guide 3, For Rectangular Hollow Section (Rhs) Joints Under Predominantly Static Loading. Comité International Pour Le Développement Et L'étude De La Construction Tubulaire, 2009.

[6] Duff, G., "Joint Behaviour of a Welded Beam-column Connection in Rectangular Hollow Sections" (Doctoral dissertation, The College of Aeronautics Cranfield, UK), 1963.

[7] Eurocode 3, Design of Steel Structures - Part 1-8: Design of Joints, European Committee for Standardization, Brussels, 2003.

[8] Hwang, W. S., Kim, Y. P. and Yoon, T. Y., "Central Angle Effect on Connection Behavior of Steel Box Beam-to-circular Column" Structural Engineering and Mechanics, 2009, Vol. 32, No. 4, pp. 531-547.

[9] Korol, R. M. and Mansour, M. H., "Theoretical Analysis of Haunch-reinforced T-joints in Square Hollow Sections" Canadian Journal of Civil Engineering, 1979, Vol. 6, No. 4, pp. 601-609.

[10] Korol, R. M. and Mirza, F. A., "Finite Element Analysis of RHS T-joints" Journal of the Structural Division, 1982, Vol. 108, No. 9, pp. 2081-2098.

[11] Lazar, B. E. and Fang, P. J., "T-type Moment Connections between Rectangular Tubular Sections” In Research Report, Sir George Williams University Montreal, 1971.

[12] Mang, F., Bucak, O. and Wolfmuller, F., "The Development of Recommendations for the Design of Welded Joints between Steel Structural Hollow Sections (T-and X-type joints).” 
In Report on ECSC Agreement 7210 SA/109 and CIDECT Program 5AD Final Report. University of Karlsruhe Federal Republic of Germany, 1983.

[13] Mashiri, F.R., Zhao, X. L. and Grundy P., "Stress Concentration Factors and Fatigue Behavior of Welded Thin - Walled CHS-SHS T-Joints Under In-Plane Bending." Engineering Structural 2005, Vol. 26, pp. 1861-1875.

[14] Mashiri, F.R. and Zhao, X. L., "Plastic Mechanism Analysis of Welded Thin-Walled T-Joints Made Up Of Circular Braces And Square Chords Under In-Plane Bending." Thin-Walled Structures, 2004, Vol. 42, pp. 759-783.

[15] Mehrotra, B. L. and Redwood, R. G., "Load Transfer through Connections between Box Sections", Canadian Eng. Instn., C-70-BR and Str, 10, 1970.

[16] Mehrotra, B. L. and Govil, A. K., "Shear Lag Analysis of Rectangular Full-Width Tube Junctions" Journal of the Structural Division, 1972, Vol. 98, No. 1, pp. 287-305.

[17] Redwood, R. G., "The Behaviour of Joints between Rectangular Hollow Structural Members" Civil Engineering and Public Works Review, 1965, Vol. 60, No. 711, pp. 1463-1469.

[18] Szlendak, J. and Brodka, J., "Technıcal Note. Strengthening Of T Moment Of RHS Joints" In ICE Proceedings, Thomas Telford, 1985, Vol. 79, No. 4, pp. 717-727.

[19] Szlendak, J., "Beam-column Welded RHS Connections", Thin-walled Structures, 1991, Vol. 12, No. 1, pp. 63-80.

[20] TS EN ISO 6892-1, "Metallic Materials - Tensile Test - Volume 1 : Test Method at ambient Temperature", The Turkish Standards Institution, 2010.

[21] Wang, W. D., Han, L. H. and Uy, B., "Experimental Behaviour of Steel Reduced Beam Section to Concrete-filled Circular Hollow Section Column Connections", Journal of Constructional Steel Research, 2008, Vol. 64, No. 5, pp. 493-504.

[22] Wardenier, J., "Hollow Section Joints" (Doctoral dissertation, TU Delft, Delft University of Technology), 1982.

[23] Zhao, X. L., "Deformation Limit And Ultimate Strength Of Welded T-Joints In Cold-Formed RHS Sections", Journal of Constructional Steel Research, 2000, Vol. 53, pp. 149-165. 